\title{
Studying the properties of heat cure acrylic resin after reinforced with polyamide fibers treated with plasma (oxygen gas)
}

\author{
Raghdaa. K. Jassim
}

B. D. S, M.Sc, Ph. D - Assist. Prof. College of Dentistry/Baghdad University

\begin{abstract}
Background: In prosthodontic dentistry, Heat cure acrylic resin is the most popular denture base material. This material still requires different methods of reinforcement .One of which can be the addition of different kind of fibers. This study aimed to investigate the effects of different concentrations of plasma treated polyamide fibers on some properties of heat cure acrylic resin.
\end{abstract}

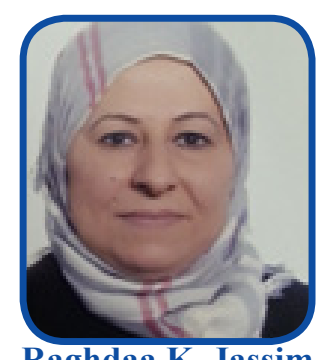

Materials and methods: All specimens were prepared from heat cure acrylic resin. plasma treated polyamide fibers were added in different concentration as follow ( $0 \%$ no fibers control, $2 \%, 5 \% \& 7 \%$ ). These fibers were treated with a plasma oxygen gas for two times $5 \mathrm{~min}$ and $10 \mathrm{~min}$.The properties of these specimens were evaluated through the following test: Transverse strength, Impact strength, Indentation hardness and surface roughness. Statistical analysis of data was done using ANOVA test.

Results: In heat cure acrylic specimens reinforced with plasma treated polyamide fiber for 10 min, the highest mean values of Transverse strength and Impact strength $(78.5 \pm 3.100) \mathrm{Mpa},(7.821 \pm 0.763) \mathrm{KJ} / \mathrm{m}^{2}$ respectively. These results observed in specimens contain (5\%) of fiber. Also, the effect of polyamide fiber treated with oxygen gas for 5 min increases transverse strength and impact strength. ANOVA test results revealed a non-significance difference among groups of specimens for indentation test only.

Conclusions: Within the limitation of this study, it can be concluded that $2 \% \& 5 \%$ of plasma treated polyamide fiber results in improvement in transverse strength, impact strength and surface roughness. While for Indentation hardness test, a statistically non significance difference was observed among all groups of specimens.

KEYWORD

Acrylic resin, polyamide, plasma, oxygen gas.

CITE THIS ARTCLE:

Jassim R. Studying the properties of heat cure acrylic resin after reinforced with polyamide fibers treated with plasma (oxygen gas). Iraqi Dent. J. 2015; 37(3):83-89. http://www.iraqidentaljournal.com



\section{INTRODUCTION}

Dental prostheses are predominantly made of heat cure acrylic resin. This material characterized by their biocompatibility, an easy handling process and natural appearance .Despite of this advantages, Heat cure resin has poor mechanical resistance (flexural strength, impact strength) (1).In the literature there is a lot of articles about the strengthening process with a different kind of fiber: carbon, polyamide, polyethylene, and glass ${ }^{(2,3,4)}$ Carbon and Kevlar fiber cannot be used because of difficulty in polishing and poor esthetic(s,b). Although polyethylene more esthetic, but the process of preparing with polymer may not be a practical in dental practice ${ }^{(7)}$.Vuorinen et al mentioned that the use of rigid rod polymer as a fillers decreases water sorption whereas the flexural strength\& solubility not affected (8).

Surface treatment of fiber is used as reinforcement in composite materials to modify the chemical \& physical properties. Salination of fiber can be used as a method to enhanced bond between fiber and acrylic resin matrix ${ }^{(9,10)}$. Plasma surface treatment used with different type of dental material including heat and light cure denture base material ${ }^{(1)}$ Also plasma surface treatment for fiber used to increase the mechanical properties of acrylic denture base material (12). As Mawade et al in 2012 refers to use plasma as an effective method for reinforcement of denture base material especially when their results indicated that plasma surface treatment of polyethylene fiber improves the impact strength significantly ${ }^{(13) .}$ It is possible to find articles about acrylic resin 
strengthen by incorporation nylon fiber Flexural strength of heat cure resin increased with the use of three types of fiber (glass fiber, aramid \& nylon) especially heat cure specimens reinforced with glass fiber have the highest flexural strength then aramid and nylon ${ }^{(14)}$.

Invitro study done by Soygun et al in 2013 investigate the mechanical and thermal characteristic of valplast and Polymethylmethacrylate denture base material containing a different type of fiber Nylon-6 and E-glass .the results revealed that fiber added a group displayed better vitreous transition and nonadhesion occur at fiber/matrix interface $e^{(15) .}$

The present study used plasma oxygen gas surface treatment to polyamide fiber and studies the effect of different concentrations of these fibers on heat cure acrylic denture base materials properties :A. Transverse strength.B. Surface roughness .C. Surface hardness. D. \& Impact strength. Also study the effect of plasma treatment time on modification of fiber reinforced heat cure acrylic properties mentioned above.

\section{MATERIALS AND METHODS:- a.Pilot study}

$1^{\text {st }}$ Pilot study was done to evaluate if plasma treatment to the surface of polyamide fiber can improve properties of resin, this was obtained by doing transverse strength test for two groups of specimens. 1st group of specimens contain plasma treated polyamide fiber $\& 2^{\text {nd }}$ group contain polyamide fibers without treatment. The results appeared that there is a marked decrease in transverse strength values of specimens contain polyamide fibers without surface treatment as compared with specimens contain plasma treated polyamide fiber. Then another pilot study was done for the selection of the type of gas suitable to be use with plasma irradiation of polyamide fiber which either oxygen or argon gas. Their results indicate that oxygen gas produces higher mean values when compared with that of argon gas.

2nd Pilot study done to select the required concentration of treated fibers. The results appeared that there was a marked decrease in transverse strength values when the concentration increase more than $7 \%$.

\section{b. Design of study}

A total number of two hundred seventy specimens were prepared from heat cure acrylic resin (super acryl plus, sofa dental a.s., Markova), they were divided into five main group according to the test used (Transverse strength, Impact strength, Indentation hardness \& Surface roughness). Each main group subdivided into four subgroup according to the concentration of plasma treated polyamide fibers used ( $0 \%$ contain no fibers control, $2 \%, 5 \% \& 7 \%$ ).for the control group 10 specimens was prepared, while for the other concentration 20 specimens in which 10 specimens contain plasma treated fibers for $5 \mathrm{~min}$ and 10 specimens contain plasma treated polyamide fiber for $10 \mathrm{~min}$.

\section{c. preparation of the fibers}

polyamide fiber(china) prepared from a continuous reel .From this $2 \mathrm{~mm}$ length of fibers were used .A cutter was used to cut this fibers. Physical properties of poly amide fiber according to the manufacturer instruction as shown in table 1

Table 1Manufacturer instruction of polyamide fiber

\begin{tabular}{|l|c|}
\hline Properties & values \\
\hline Density & $1.14 \mathrm{gm} / \mathrm{cm} 3$ \\
\hline Elongation to break & Very good \\
\hline Resiliency & Good \\
\hline Tenacity & $4.4-8.5 \mathrm{gm} / \mathrm{cm}$ \\
\hline Melting point & $250 \mathrm{C}$ \\
\hline Ability to protest friction & Excellent \\
\hline Color & white \\
\hline
\end{tabular}

\section{d. surface modification of the fibers:}

oxygen gas plasma surface treated fibers were used in this study as follow:-

$1^{\text {st }}$ step: in this step, all fibers were cleaned with methanol in an ultrasonic cleaning device for a $5 \mathrm{~min}$, then plasma treatment was done using a device called Dc glow discharge plasma treatment. The principle components are: (1) the plasma chamber (2) Vacuum pumps system (rotary and turbo pumps (3) ,current measurements (4 cylindrical stainless steel vacuumed chamber (5) penning and pirani heads and readers.

Samples were cleaned for five minutes using ultrasonic cleaning device in Methanol as follow:

1.Polyamide fibers were put in a beaker filled with $5 \%$ methanol, this beaker putted in the ultrasonic cleaner which was filled with distilled water under vibration for five minutes.

2.The samples were dried using a hair dryer for $1 \mathrm{~min}$, then immediately the cleaned sample is placed in the sample holder inside the chamber. The samples to be treated were placed on the cathode surface 


\section{Prosthodontics}

in the center of the cathode assembly of the glowdischarge plasma system The distance between the electrodes was $4.5 \mathrm{~cm}$ and the power supply and voltage adjusted to produce enough current according to the size of the sample. Then the Plasma chamber was evacuated to pressures better than $5 \times 10^{-3}$ mbar using a mechanical rotary pump and then using a turbo pump to increase the pressure to $2 \mathrm{X} 10^{-1}$ mbar, when the plasma chamber evacuated, the oxygen gas was introduced in the chamber. The time needed for dc-glow discharge of oxygen (oxygen plasma) to be ignited and applied to each samples was one hour period. The sample was sputter cleaned until all micro arcs disappear and a uniform glow could be seen throughout the sample. This process was performed to ensure the exposure of the active surface of the samples to glow plasma and removing the native oxide and contaminated layer. At the end of this time the voltage turned off and wait for $15 \mathrm{~min}$ for the gas to be evacuated, so the specimens removed and covered with cling film until testing time. The holding times were 5 and $10 \mathrm{~min}$. The applied voltage was $(1 \mathrm{KV})$. This was according to the amount and type of materials used (polyamide).every time of exposure to plasma 0.5 $\mathrm{M}$ of fiber silk cut into $2 \mathrm{~mm}$ and exposed to plasma .Polyamide fiber treated with oxygen gas for two periods of time (5min\&10min). as shown in fig 1

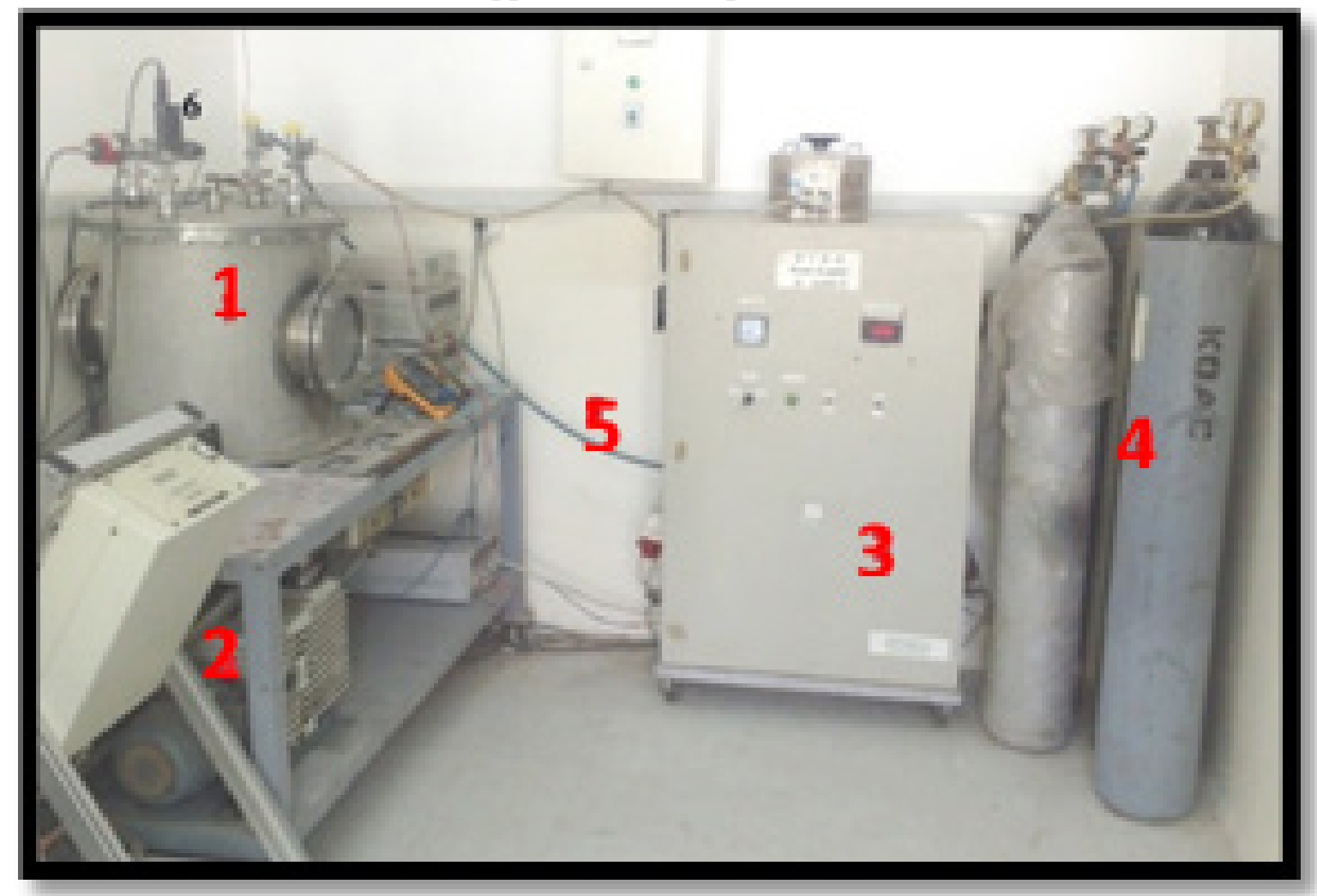

Fig (1) component parts of Dc- glow discharge plasma

\section{e. Metal mold preparation}

Two different metal pattern were constructed by cutting stainless steel plate into a desired dimension .for surface roughness, indentation hardness and transverse strength the metal mold were constructed with the following dimensions $(65 \times 10 \times 2.5) \mathrm{mm}$ length ,width \& depth respectively ${ }^{(16)}$.while dimensions for the impact strength test were $(80 \times 10 \times 4) \mathrm{mm}$ respectively ${ }^{(17)}$.

\section{f. Proportioning and mixing of acrylic}

Addition of fiber:- the percentages of poly amide fiber $2 \%, 5 \%$, and $7 \%$ were added to acrylic powder by a weight addition. An electronic balance was used (Sartorius BP 30155, Germany). After addition, the required amount of plasma treated fiber to the powder, PMMA powders with fiber were mixed with
MMA monomer. The proportioning and mixing of acrylic resin was done $\mathrm{P} / \mathrm{L}$ ratio according to manufacturer instruction. The recommended ratio is $22 \mathrm{~g}$ powder and $10 \mathrm{ml}$ liquid. The conventional method for complete denture construction was followed. The manufacturer instruction for the curing cycle was followed which include immersion of the flask into the cold water until it becomes boil for $45 \mathrm{~min}$ then the flask removed and left for cooling at room temperature.

According to ANSI/ADA specification No.12 for denture base material, all the specimens were conditioned in distilled water for $48 \mathrm{~h}$ at $73 \mathrm{C}^{\circ}$ before testing ${ }^{(18)}$.

\section{g. Test utilized to examine the properties}

1. Impact strength test: - Impact strength test was 
conducted following the procedure given by the ISO 179.In this research, the type of impact test device used was charpy type (N. 43-1, testing machines, INC. USA), this can be used for unnotched specimen. "The specimen was supported horizontally at its ends, and struck by a free swinging pendulum which released from a fixed height in the middle. A pendulum of 2 joules testing capacity was used. The charpy impact strength of the unnotched specimens were calculated in $\mathrm{KJ} / \mathrm{m}^{2}$ according to the following equation: " Impact strength $=\mathrm{X} 10^{3}(19)$ Where

$\mathrm{E}$ : is the impact absorbed energy in joules,

$\mathrm{B}$ : is the width in millimeters of test specimens, D: is the thickness in millimeters of test specimens.

2. Transverse strength:- this test was achieved using an Instron testing machine (Instron Corporation, 1122 , canton mass, ( each specimen was positioned on a bending fixture, consisting of 2 parallel supports (50) $\mathrm{mm}$ a part, the full scale load was $50 \mathrm{~kg}$, and the load was applied with a cross head speed of $1 \mathrm{~mm} / \mathrm{m}$ in by a rod placed centrally between the supports ma king deflection until fracture occured.

The transverse bend strength was calculated $u$ sing the following formula:

Transverse strength $=3 . P . \mathrm{L} / 2 \cdot \mathrm{b} \cdot \mathrm{d}^{2}$ where ${ }^{(19)}$

$\mathrm{P}$ : is the peak load.

$\mathrm{L}$ : is the span length.

$\mathrm{b}$ : is the sample width.

$\mathrm{d}$ : is the sample thickness.

3. Indentation hardness test: - Surface hardness was determined using a durometer hardness tester from type shore D, (hardness tester-th 210, time group Inc. Italy), which is suitable for heat cure denture base material. This device is supplied with bluntpointed indenter the diameter of indenter is $0.8 \mathrm{~mm}$ .And this was tapers to a cylinder of $1.6 \mathrm{~mm}$ diameter. The indenter is connected with a digital scale. The digital scale was graduated from 0 to 100 units. Measurements were obtained directly from the digital scale .Five measurements were recorded directly from the surface of each specimen. This was obtained from the same selected area of each specimen), then the average value of these reading was obtained.

\section{Surface roughness test}

The profilometer device (Surface roughness tester SRT-) was used to study the effect of Plasma treatment of fiber on surface roughness. This device is supplied with a surface analyzer sharp stylus made from diamond. A maximum distance can be move is $11 \mathrm{~mm}$. Three measurements were obtained from different area of each specimen (the same selected area of each specimen), then the average off these readings was calculated. This device can give different roughness parameter, but $\mathrm{Ra}$ is the most common (RA, RT, RS, RSK, RQ, RP, RZ, RV, RSM). Ra value $(\mu \mathrm{m})$ described the surface roughness of surface and is defined as the mean value of all absolute distance of the roughness profile from the mean line within the measuring distance The results of Ra were included in this study since it obtained directly from the device.

5. Statistical analysis of data was performed using SPSS 17 and the result of the study were analyzed through the following statistical methods:

1- Descriptive statistic (Mean, Standard deviation (S.D), Standard error (S.E)

2- Inferential statistics : ANOVA ( one-way analysis of variance test) for assessing differences between more than 2 groups, LSD (Least Significant Difference test) was used for examining differences between each group. Value more than 0.05 considered as statistically non-significant while P. value less than 0.05 accepted as significant

$P \geq 0.05$ non-significant

$\mathrm{P}<0.05$ significant

$\mathrm{P} \leq 0.01$ highly significant

\section{RESULTS}

The mean distribution, standard deviation values of Transverse strength, impact strength, indentation har dn e s s \&surface roughness of heat cure resin rei nf o $\mathrm{r}$ ced with plasma treated polyamide fibers for $5 \mathrm{~min}$. presented in a table (1). In general the highest mean values were (74.6) MPa \& 7.033KJ/ $\mathrm{m}^{2}$ fo $\mathrm{r}$ transverse strength and impact strength respectively in specimens containing $5 \%$ of plasma treated polyamide fiber, While the results of surface rou gh ness \& indentation hardness were (2.58) \& $(75.3) \mathrm{KJ} / \mathrm{m}^{2}$ respectively in specimens containing $7 \%$.

ANO VA test indicated a highly significance dif ference for (Transverse strength test, impact strength test \&surface roughness. While indentation tes $t$ showed no statistically significance difference (p> 0.05) among the groups of the following mea $n$ values $(77.3 \pm 2.451,78.5 \pm 3.205,75+4.082$, $75+4.347)$.as shown in table (1).

The mean distribution, standard deviation values \& the results of ANOVA test in a Table(2). In this table, the results of ANOVA test revealed a highly significance difference for transverse strength, impact strength, \&surface roughness test of heat cure specimens contain plasma treated polyamide fibers for $10 \mathrm{~min}$, while for the indentation hardness, it was a non-significance. 
In the results of LSD test, a non-significance difference between control and $2 \%$ group $(\mathrm{p}=0.46)$, also non-significant difference between control and 5\%group $(\mathrm{p}=0.98)$ for transverse strength only as shown in the table (3) .The results of LSD test in a table (4) revealed a non-

Table (1) ANOVA test for the means values of Transverse strength, Surface roughness, Impact strength and Indentation

Hardness of heat cure contain plasma treated polyamide fiber for $5 \mathrm{~min}$

\begin{tabular}{c}
$\%$ of polyamide fiber \\
\hline $0 \%$ control \\
$2 \%$ \\
$5 \%$ \\
$7 \%$ \\
ANOVA \\
TEST
\end{tabular}

significance difference between control and $2 \%(\mathrm{p}=0.104)$, and between control and $5 \%(p=0.013)$ for impact strength. Also a non-significant between control and $2 \%(\mathrm{p}=0.073)$ for Transverse strength only.

Table (2) ANOVA test for mean values of Transverse strength, Surface roughness, Impact strength and Indentation Hardness of heat cure contain plasma treated poly amide fiber for $10 \mathrm{~min}$

\begin{tabular}{|c|c|c|c|c|c|c|c|c|c|}
\hline \multirow[t]{2}{*}{$\begin{array}{c}\% \text { of } \\
\text { polyamide } \\
\text { fillers }\end{array}$} & \multirow[t]{2}{*}{$\begin{array}{c}\text { No for } \\
\text { Each test }\end{array}$} & \multicolumn{2}{|c|}{$\begin{array}{c}\text { Transverse } \\
\text { strength } \\
M P a\end{array}$} & \multicolumn{2}{|c|}{$\begin{array}{c}\text { Surface roughness } \\
\mu m\end{array}$} & \multicolumn{2}{|c|}{$\begin{array}{c}\text { Impact } \\
\text { strength } \\
K J / m^{2}\end{array}$} & \multicolumn{2}{|c|}{ Indentation Hardness } \\
\hline & & Mean & $S D$ & Mean & $S D$ & Mean & $S D$ & Mean & $S D$ \\
\hline $0 \%$ control & 10 & 70 & 6.073 & 1.714 & .193 & 5.702 & .627 & 77.3 & 2.451 \\
\hline $2 \%$ & 10 & 74.7 & 6.147 & 1.133 & .309 & 7.244 & .767 & 74.1 & 6.436 \\
\hline $5 \%$ & 10 & 78.5 & 3.100 & 1.469 & .267 & 7.821 & .763 & 75 & 5.704 \\
\hline $7 \%$ & 10 & 61.6 & 6.653 & 2.530 & .421 & 3.388 & .650 & 75.7 & 4.967 \\
\hline ANOVA & $\mathrm{F}$ value & \multicolumn{2}{|c|}{15.598} & \multicolumn{2}{|c|}{37.043} & \multicolumn{2}{|c|}{68.363} & \multicolumn{2}{|c|}{0.694} \\
\hline TEST & sig & \multicolumn{2}{|c|}{.000} & \multicolumn{2}{|c|}{.000} & \multicolumn{2}{|c|}{.000} & \multicolumn{2}{|c|}{562} \\
\hline
\end{tabular}

Table (3) LSD test between groups of Impact strength and Transverse strength test\& Surface Roughness for specimens contain plasma treated polyamide fibers for $5 \mathrm{~min}$

\begin{tabular}{|c|c|c|c|c|c|c|c|}
\hline \multirow{2}{*}{\multicolumn{2}{|c|}{$\begin{array}{c}\text { Groups of } \\
\text { poly amide fillers } \\
(P A-F)\end{array}$}} & \multicolumn{2}{|c|}{ Impact strength } & \multicolumn{2}{|c|}{ Transverse strength } & \multicolumn{2}{|c|}{ Surface Roughness } \\
\hline & & \multirow{2}{*}{$\begin{array}{c}\begin{array}{c}P \\
\text { value }\end{array} \\
1.899\end{array}$} & \multirow{2}{*}{$\begin{array}{c}\begin{array}{c}\text { Mean } \\
\text { difference }\end{array} \\
0.000\end{array}$} & \multirow{2}{*}{$\begin{array}{c}\begin{array}{c}P \\
\text { value }\end{array} \\
2.000\end{array}$} & \multirow{2}{*}{$\begin{array}{c}\text { Mean } \\
\text { difference }\end{array}$} & \multirow{2}{*}{$\begin{array}{c}\begin{array}{c}P \\
\text { value }\end{array} \\
0.616 \\
\end{array}$} & \multirow{2}{*}{$\begin{array}{c}\text { Mean } \\
\text { difference }\end{array}$} \\
\hline \multirow{3}{*}{ control } & $2 \%(\mathrm{PA}-\mathrm{F})$ & & & & & & \\
\hline & $5 \%(\mathrm{PA}-\mathrm{F})$ & 1.331 & 0.000 & 4.600 & 0.98 & 0.165 & 0.140 \\
\hline & $7 \%(\mathrm{PA}-\mathrm{F})$ & 1.353 & 0.000 & 6.000 & 0.033 & 0.866 & 0.000 \\
\hline \multirow{2}{*}{$2 \%$} & $5 \%(\mathrm{PA}-\mathrm{F})$ & 3.252 & 0.074 & 2.600 & 0.343 & 0.451 & 0.000 \\
\hline & $7 \%(\mathrm{PA}-\mathrm{F})$ & 0.568 & 0.000 & 8.000 & 0.005 & 1.482 & 0.000 \\
\hline $5 \%$ & $7 \%$ ( PA-F) & 2.684 & 0.000 & 10.600 & 0.000 & $1.031-$ & 0.000 \\
\hline
\end{tabular}

* $\mathrm{P}<0.05$ Significant, $\mathrm{P}>0.05$ Non significant, $\mathrm{P}<0.01$ High significant. 
Table (4) LSD test between groups of Impact strength and Transverse strength test\& Surface Roughness for specimens with plasma treated poly amide fillers for $10 \mathrm{~min}$

\begin{tabular}{|c|c|c|c|c|c|c|c|}
\hline \multicolumn{2}{|c|}{$\begin{array}{c}\text { Groups of } \\
\text { poly amide fillers (PA-F) }\end{array}$} & \multicolumn{2}{|c|}{ Impact strength } & \multicolumn{2}{|c|}{$\begin{array}{l}\text { Transverse } \\
\text { strength }\end{array}$} & \multicolumn{2}{|c|}{ Surface Roughness } \\
\hline & & $\begin{array}{c}P \\
\text { value }\end{array}$ & $\begin{array}{c}\text { Mean } \\
\text { difference }\end{array}$ & $\begin{array}{c}P \\
\text { value }\end{array}$ & $\begin{array}{c}\text { Mean } \\
\text { difference }\end{array}$ & $\begin{array}{c}P \\
\text { value }\end{array}$ & $\begin{array}{c}\text { Mean } \\
\text { Difference }\end{array}$ \\
\hline \multirow{3}{*}{ control } & $2 \%(\mathrm{PA}-\mathrm{F})$ & .000 & .104 & 4.700 & .073 & 0.581 & .000 \\
\hline & $5 \%(\mathrm{PA}-\mathrm{F})$ & .000 & .013 & 7.9700 & .000 & 0.245 & .085 \\
\hline & 7\%(PA-F) & .000 & .000 & 8.400 & .000 & 0.816 & .000 \\
\hline \multirow{2}{*}{$2 \%$} & $5 \%(\mathrm{PA}-\mathrm{F})$ & .077 & .000 & 3.2700 & 207 & 0.336 & .020 \\
\hline & $7 \%(\mathrm{PA}-\mathrm{F})$ & .000 & .000 & 1.3100 & 000 & 1.397 & .000 \\
\hline $5 \%$ & $7 \%$ (PAF) & .000 & .000 & 1.6300 & .000 & 1.061 & .000 \\
\hline
\end{tabular}

* $\mathrm{P}<0.05$ Significant, $\mathrm{P}>0.05$ Non significant, $\mathrm{P}<0.01$ High significant

\section{DISCUSSIONS}

Inthisstudy,polyamidefiberswereused toimprove properties of heat cure resin. Nylon(polyamide) is a crystalline polymer, low density, high strength, insoluble in almost all common solvent\& it is less likely to alter esthetic ${ }^{(20,21)}$. Impregnation of reinforcing fiber with the resin allows fiber to come into contact with polymer matrix, optimal adhesion between the fiber and polymer matrix is essential. This is for strengthen of the composite. Plasma surface treated fiber used to improve adhesion with the acrylic resin denture base material.

Denture base is subject to much stress intraorally from repeated masticatory force leads to fatigue phenomena, while extraorally, high impact force can occur if denture is dropped and a fracture of denture base occurred. Ideally, denture base should have sufficient high strength to prevent breakage on accidental dropping, but not at the expense of the other properties. The transverse strength test used in this study because of the type of load applied is similar to that load applied on denture during mastication ${ }^{(1)}$

\section{Transvers strength}

The addition of concentrations $(2 \% \& 5 \%)$ of plasma treated polyamide fiber increases the values of transverse strength as compared with control. This might be due to even distributions of fiber can limit the segment motion of the molecular chain. Plasma surface treatment used to modify the chemical \&physical properties of fiber surface, especially when use oxygen gas. Plasma oxygen gas is known to be very reactive etchant .This reactivity is due to a reaction of atomic oxygen with fiber surface, which is the starting point for the etching process. This results in agreement with Unalan et al ${ }^{(22)}$ and Kamble et al ${ }^{(23)}$ and disagree with Almomen ${ }^{(24)}$ and this might be due to the difference in materials and methodology. Also in literature, mechanical strengthening of polymers with fiber related to many factors includes type .orientation, form, quantity, concentration and mode of adhesion with the fibers besides the length of fiber used in reinforcement of acrylic .Addition of short increases the transvers strength of matrix material (25) .In others study2, 4, 6mm length of fiber do not significantly affect the transvers strength of material (26).

Impact strength:this test was applied for unnotched specimens

The results of an impact strength increase as the concentration of fiber increase, this can be due to the difference in modulus of elasticity of fiber and acrylic matrix, fiber is more flexible, elastic in nature, that's may increase the strength of the material. And plasma used for etching or gasifying substrate material which might lead to improve adhesion properties of fiber with acrylic matrix .Also" the presence of fibers which might offers the load a long their length to enhance the strength of material, resulting in a higher absorption of energy as compared with the control specimens " (27). This agree with result obtained by Mohammed and Ismial (12).

\section{Surface roughness:}

The addition of $2 \% \& 5 \%$ of plasma treated polyamide fiber decrease the values of surface roughness as compared with control. This might be due to the small concentrations of fiber and well distribution. These can results in a few number of fiber appeared on the surface of the specimen .Also, this can explain the results obtained from the addition of $7 \%$ of fiber. At this concentration, the results indicate an increase in the surface roughness mean value which means that increase amount of fiber lead to a large number of fiber observed in the surface of a specimen.

\section{Surface hardness:}

In this study, shore (D) hardness tester was used 
.this is suitable for measuring the hardness of acrylic resin, Shore durometer type (D) hardness tester can eliminate problem associated with elastic recovery owing to its use as a method measures the depth of the loaded indenter under loading condition directly by screen .And shows the number of it ${ }^{(22)}$

The results of the present study revealed a nonsignificance difference among groups of specimens contain $0 \%$ plasma treated polyamide fiber, $2 \%$ plasma treated polyamide fibers for $5 \& 10 \mathrm{~min}$ and $5 \%$ plasma treated poly amide fiber for $5 \& 10 \mathrm{~min}$ and $7 \%$ plasma treated polyamide fiber for $5 \& 10 \mathrm{~min}$.this results disagreement with the results of Mohammed and Ismail in $2013^{(12)}$ this might be due to the differences in type of fiber used and methodology.

\section{CONCLUSIONS}

Within the limitation of this study, it can be concluded that the addition of $2 \% \& 5 \%$ of plasma treated polyamide fiber at $10 \mathrm{~min}$ can improve the properties of heat cure resin, while the addition of fibers in $7 \%$ and more leads to adverse effect.

\section{REFERENCES}

1. Sakaguchi R.L, Powers J.M. and contributors. Graig's Restorative Dental Materials. 13th ed. Elsevier: Mosby; 2012: pp191.

2. Vallitu P.K., Review of fiber reinforced denture base resins J.Prosthet.Dent.1996:5, 4,270-76.

3. Vallitu $P$ K. Review of methods used to reinforce PMMAresin.J.Prosthet.Dent1995 4(3)183-187.

4. Mathew M, Shenoy K, Ravishankar KS Flexural Strength of E-glass-reinforced PMMA. Int, J Experiment Dent Sci 2014; 3(1):24-28.

5. Yazadanie $\mathrm{N}$ and Mahood M, Carbon fiber acrylic resin composite an investigation of transverse strength ,J prosth. Dent.1985;54:543-77.

6. Berrong J, M, Weed R, M, Yong J, M: Fracture resistance of Kevlar-reinforced poly methylmethacerylate resin: a preliminary study .Int. J Prosthodontic.1990; 3:391-5.

7. Gutterride DL. The effect of including ultra-high modulus polyethylene fiber on the impact strength of acrylic resin. Brt. Dent J.1988:164:77-80. IVSL

8. Vuorinen AM and Vallitu PK rigid rod polymer fillers in acrylic denture adhesive resin system university of Turki thesis 2010

9. Prasad H, Kalavathy, Mohammed H, S Effect of glass fiber and silane treated glass fiber reinforcement on impact strength of maxillary complete denture. Annals and Essences of Dentistry V III :'( 4) 2011, pp.7-11.

10. Yun S,H Cho D, ., Kim J, Lim S Lee G, Park M, Lee S Effect of silane coupling agents with different organofunctional groups on the interfacial shear strength of glass fiber/Nylon 6 composites. J Materials Science Letters; 2003, 22 Issue 22, p1591.

11. Allia $\mathrm{Kb}$ and Raghdaa KJ The effect of plasma on transverse strength, surface roughness and Candida adhesion of two types of acrylic denture base materials (Heat cure and light cure) J .Bagh College Dent 2012, 24(2), 10-17.

12. Mohammed WI and Ismail I J The effect of addition of untreated and oxygen plasma treated polypropylene fibers on some properties of heat cured acrylic resin ) J .Bagh College Dent .2013 25,4,33-38.

13. Mawada TK, Dange SP, Thakre MB, Kamble VD. The effect of fiber reinforcement of impact strength of heat PMMA denture base resin: Invitro study \&SEM analysis J.adv.Prosthet dent.2012:4(4)30-36.

14. John J, Gangadhar SA, Shah I: Flexural strength of heat Polymethylmethacrylate resin reinforced with glass, armide, or nylon fiber. J Prosth. Dent2001; 86: 424-427).

15. Soygeun K, Bolayir G, Boztug A, Mechanical and thermal properties of polyamide versus reinforced PMMA denture base material. J.adv.Prosthodont 2013:5(2),153-160 IVSL

16. American Dental Association specification ,Guide to dental materials and devices, 7th ed., Chicago Illinois. 1975

17. ISO 179-1 (2000) international organization for standardization

18. American Dental Association Specification No.12; 1999 for denture base polymers Chicago. Council on dental materials and devices.

19. Anusavice K.J. (2008): "Philips science of dental material". 11th Ed, Middle East and African edition, Ch7, Ch22, p: 143-166,721-756.

20. AnKohil S \& Bhatia S. Polyamide in dentistry.Int.J scientific study.2013, 1, 1, 20-25.

21. Lewin M, Handbook of fiber chemistry, Taylor \&Francis group UK 3rd ed.2007.

22. Unalan F, Dikbas I, Gurbuz O. Transverse strength of Polymethylmethacrylate reinforced with different forms and concentrations of E-Glass fibers. OHDMBSC 2010; IX, (3) PP 144-7.

23. Kamble VD, Porkhedkar RD, Mowade TK. The effect of different fiber reinforcement on flexural strength of provisional and restorative resin: an in-vitro study. J Adv Prosthodont 2012; 4(1): 1-6.

24. Al- Momen MM. Effect of reinforcement on strength and radiopacity of acrylic denture base material. A master thesis, Department of Prosthodontics, University of Baghdad, 2000.

25. Marei MK. Reinforcement of denture base resin with glass filler. J Prosthodont1999; 8: 1, 18-26.

26. Chen SY, Liang WM, Yen PS. Reinforcement of acrylic denture base resin by incorporation of various fibers $\mathrm{J}$ Biomed Mater Res 2001;58:2038. 